\title{
EL ROL DEL ÁMBITO LOCAL EN LA ADOPCIÓN \\ DEL MAINSTREAMING DE GÉNERO \\ EN POLÍTICAS DE EMPLEO
}

The role of the local government in the adoption of
gender mainstreaming in employment polices

\author{
PAULA OTERO-HERMIDA \\ Universidad Politécnica de Valencia \\ pauother@upvnet.upv.es
}

\author{
RAMÓN BOUZAS LORENZO \\ Universidad de Santiago de Compostela \\ ramon.bouzas@usc.es
}

Cómo citar/Citation

Otero-Hermida, P. y Bouzas Lorenzo, R. (2018).

El rol del ámbito local en la adopción del mainstreaming de género en políticas de empleo.

Revista de Estudios Políticos, 182, 191-224.

doi: https://doi.org/10.18042/cepc/rep.182.07

\section{Resumen}

Las políticas de empleo han sido largamente estudiadas desde perspectivas de género, si bien son muy escasos los estudios desarrollados en el ámbito local. Este estudio incluye una propuesta analítica para observar el mainstreaming de género en las políticas locales de empleo y ofrece resultados sobre las relaciones que existen entre las problemáticas de género detectadas y las acciones desarrolladas por los Gobiernos locales. La investigación evalúa datos provenientes de 198 municipios de mediano tamaño en Espańa, estudiados desde una aproximación cuantitativa complementada con estudios de caso.

El estudio muestra los déficits observados en las políticas implementadas, así como las limitaciones del rol jugado por el ámbito local, mostrando que los municipios mayormente reproducen las acciones que ya están siendo desarrolladas por actores supramunicipales, como las comunidades autónomas o el Gobierno central. En el 
marco de una política verdaderamente multinivel, los Gobiernos locales no ofrecen un rol singular, diluyendo las potenciales ventajas de la proximidad. Las conclusiones obtenidas pueden contribuir a una mejor reconstrucción de estas políticas en un escenario emergente poscrisis.

\section{Palabras clave}

Gobierno local; género; mainstreaming; empleo; responsabilidad social.

\section{Abstract}

Employment policies have been extensively studied from a gender perspective. Yet studies in local arenas have been scarce. The study suggests a framework to check the adoption of a gender mainstreaming focus in local employment policies and highlights outcomes regarding the relationship between gender issues and local government policy implementation. Using both quantitative (survey) - qualitative (case study) research techniques, data gathered from 198 Spanish middle size towns have been analyzed.

This research underlines the shortfalls of local employment policies and the limitations of the local authorities' role. It also demonstrates that local governments use to take after the policy-making of higher level public administrations such as regional or central governments. As it is shown, within the framework of a multilevel policy, local governments do not use to play a particular role, therefore breaking down any potential advantage gained from proximity to users. Conclusions of the study might contribute to a better design of these policies in the current post-crisis scenario.

\section{Keywords} bility.

Local government; gender; mainstreaming; employment policy; social responsi- 


\section{SUMARIO}

I. INTRODUCCIÓN. II. POLÍTICAS DE EMPLEO E IGUALDAD DE GÉNERO EN EL MARCO EUROPEO: PROBLEMAS Y NUEVOS FOCOS EN LA POLÍTICA. III. POLÍTICAS DE IGUALDAD Y DE EMPLEO EN ESPAÑA: CONTEXTO ESTATAL Y AUTONÓMICO. IV. MÉTODO. V. RESULTADOS DEL CUESTIONARIO: 1. Instrumentos generales de mainstreaming. 2. Medidas generales por la igualdad en el empleo. 3. Acciones específicas por la igualdad en el empleo: 3.1. Actuaciones dirigidas a la Administración pública local en el ámbito del empleo. 3.2. Actuaciones dirigidas a personas inactivas o desempleadas. 3.3. Actuaciones dirigidas a trabajadoras y trabajadores. 3.4. Actuaciones dirigidas a emprendedores/as y promoción empresarial. 3.5. Actuaciones dirigidas a empresas. 3.6. Actuaciones dirigidas al área rural. V. HALLAZGOS EN LOS ESTUDIOS DE CASO. VI. CONCLUSIONES. BIBLIOGRAFía.

\section{INTRODUCCIÓN}

En la cultura de las sociedades democráticas industrialmente avanzadas, el empleo ocupa un lugar preeminente en la conformación de los roles sociales y la propia identidad. El empleo es la vía fundamental para acceder a ingresos económicos y favorece la creación de redes personales y el desarrollo de las propias capacidades.

Las distintas olas del feminismo han remarcado la importancia de la independencia fruto de realizar un trabajo remunerado, así como la necesidad de liberar el talento profesional femenino, retenido por los roles de género tradicionales en la esfera doméstica, invisible y no reconocida. Su importancia ha sido reconocida en las políticas públicas, siendo las de igualdad en el empleo las políticas de género más desarrolladas en Europa (Lombardo, 2004), a pesar de concitar diferentes visiones sobre su formulación, así como posiciones diversas en torno a su impacto final.

El ámbito local es citado como un ámbito de especial relevancia desde el nacimiento del concepto de mainstreaming de género, tanto en la IV Conferencia Mundial de la Mujer de Pekín (1995) como en los documentos fundacionales del mainstreaming en Europa, que lo definen como la incorporación de la perspectiva de género en el conjunto de las políticas públicas por parte de sus actores habituales (Consejo de Europa, 1999). Por su parte, el desarrollo local de las políticas de empleo es una aspiración largamente planteada, dada la necesidad de adecuar la oferta y la demanda de empleo a las cambiantes 
actividades económicas en cada localidad, así como a crecientes perspectivas de desarrollo endógeno.

Pese a su falta de estudio comparado, las acciones de igualdad en el empleo en el ámbito local se desarrollan ampliamente en la práctica y son recogidas en la mayoría de los planes de igualdad municipales, así como en otros instrumentos de mandato, como la legislación en materia de igualdad, donde se señala la necesaria participación local en este plano.

En respuesta a la pregunta sobre cómo se articulan las acciones de igualdad en el empleo en el ámbito local español, este trabajo examina la articulación de las iniciativas municipales en materia de igualdad en el empleo local en un contexto favorable a las políticas de género (2009) — durante el primer Gobierno paritario de la democracia española y tras el reconocimiento de la competencia municipal en relación con el mainstreaming de género-. Igualmente, se observa qué contenidos abarcan, se debate el rol del ámbito local en el desarrollo de una política de igualdad en el empleo necesariamente multinivel y se ahonda en las posibles acciones a desarrollar por la igualdad de género en el empleo en el nivel administrativo local.

Estas cuestiones se abordan tomando como referencia los datos recabados en 198 municipios españoles de mediano tamaño (entre 25000 y 100000 habitantes). El análisis de la información de los casos estudiados, además de responder a los propósitos expuestos, pone de manifiesto que los municipios tienden a reproducir el enfoque y modelo de ejecución de estas políticas adoptado por Administraciones supramunicipales en detrimento del cultivo de actuaciones inherentes a su nivel y su proximidad a la ciudadanía.

En suma, dado el desmantelamiento de las políticas de igualdad acaecido en España durante la Gran Recesión (2008-2016) (Lombardo y León, 2015; Alonso y Paleo, 2014; Diz y Lois, 2011), en aras a generar conocimiento de utilidad futura, este trabajo pretende arrojar luz sobre las decisiones que se han tomado en el área local de igualdad en el empleo, conocer sus resultados $y$ aportar ideas que permitan reconducir próximas iniciativas.

\section{POLÍTICAS DE EMPLEO E IGUALDAD DE GÉNERO EN EL MARCO EUROPEO: PROBLEMAS Y NUEVOS FOCOS EN LA POLÍTICA}

Las Directrices Europeas por el Empleo 2005/2008 ${ }^{1}$ se fundamentaron sobre cuatro pilares: empleabilidad, adaptabilidad, espíritu de empresa e

Decisión 2005/600/CE del Consejo, de 12 de julio de 2005, relativa a las Directrices para las políticas de empleo de los Estados miembros (DO L 205 de 12-7-2005). 
igualdad de oportunidades. Por su parte, la Estrategia Europea 2020 (Comisión Europea, 2010), definida para lograr un crecimiento sostenible, inteligente e integrador, asume como primer objetivo lograr que el $75 \%$ de las personas entre 20 y 64 años se encuentren empleadas. Desde 1996 existen estándares para ratios de empleo femenino en el marco de la Estrategia Europea de Empleo.

El crecimiento de las ratios de personas empleadas puede contar con múltiples motivaciones. Entre ellas, la necesidad de alinear los objetivos europeos de mayor protección social con una estructura económica capaz de sostenerlos, aspecto ya prioritario antes del estallido de la Gran Recesión (Esping-Andersen, 2002; 2008). Para ello, Europa fija distintos objetivos, entre los que se encuentran el déficit cero o la incorporación de más empleados y empleadas para sumar contribuciones al sistema público. El empleo femenino contaría en este caso con mayores posibilidades de crecimiento neto, dada la mayor proporción de mujeres inactivas en edad de emplearse. Debe considerarse esta cuestión como uno de los aspectos clave en la promoción de la política, además de las reivindicaciones feministas (Navarro et al., 2004).

Independientemente de las motivaciones, los objetivos nacen en una realidad desigual de género en el mercado de trabajo, que las políticas europeas han abordado de forma sistemática a través de la incorporación del mainstreaming de género desde los años noventa.

La prioridad concedida a las políticas de empleo y su enfoque han sido debatidos en el seno del análisis feminista, observándose la raíz de las problemáticas generadas en la división entre la esfera productiva/pública/remunerada o reproductiva/privada/no remunerada. La división sexual de estos procesos, otorgando la dimensión privada, reproductiva y no remunerada ni socialmente valorada a las mujeres, tiene un impacto notable en la vida de las personas, derivado fundamentalmente del fenómeno de ocultación de esta realidad en los procesos económicos que vivimos y que son analizados a través de las ciencias sociales y la economía (Mayordomo y Carrasco, 2000). Existe «otra economía», la de las transferencias sin intercambio o donaciones, tan imprescindible como conectada con la economía de intercambio (Boulding, 1976).

Esta cuestión toma especial relevancia dado que, en las múltiples políticas de género europeas, las políticas de igualdad en el empleo son tan preeminentes que en la práctica a menudo se confunde igualdad de género - cuestión global- con la igualdad de trato en el empleo, limitando la construcción de otros regímenes de género. Esta limitación se articula siguiendo la primera ruta hacia la igualdad descrita en el dilema Wollstonecraft mediante la extensión a las mujeres de las mismas — exactamente las mismas - oportunidades disfrutadas por los hombres - es decir, un empleo remunerado (Lombardo, 2003) - sin tener en cuenta diferentes situaciones de partida. Entre otras de 
las limitaciones derivadas del planteamiento de las políticas de igualdad en el empleo se encuentran las expuestas por Walby (2004):

- En primer lugar, inicialmente, la Unión Europea restringía sus políticas al empleo estándar entendido a tiempo completo y con contratación estable. Muchas mujeres no participan de este tipo de empleo, por lo que el impacto de las regulaciones europeas era cuestionable. Posteriormente, la UE incluyó aspectos de género en el trabajo precario y a tiempo parcial, mejorando la evaluación del impacto de las posibles políticas.

— Las leyes de igualdad de trato, muy focalizadas en el ámbito del empleo, reproducen la visión masculina del hombre trabajador y ciudadano, lo que implica que las raíces de la desigualdad no se abordan. La UE fracasaría a la hora de reconocer necesidades diferenciales para mujeres que responden a necesidades de cuidado. Una de las principales propuestas europeas al respecto es la propuesta de subsidiar dicho cuidado, cuestión que, no obstante, se deja en manos de los Estados miembros, sujetos a disciplina presupuestaria, lo cual limita la implementación de políticas de bienestar. En cualquier caso, sí se reconoce el papel que han tenido las directivas europeas con respecto a la paternidad, incidiendo en el rol de padre trabajador y crecientemente cuidador. Por último, se cuestiona que la provisión estatal sea la única manera de solucionar esta cuestión.

- Se critica que la orientación al mercado de la Unión Europea ha dejado desatendidas grandes áreas de la desigualdad, como es la violencia contra las mujeres, la preferencia sexual o el aborto. Sin embargo, en este caso se matiza también que a través de esa orientación mercantil se ha abierto la libre competencia en clínicas que ofrecen el aborto como servicio, así como se ha terminado legislando acerca de la imposibilidad de discriminación por orientación sexual y se han favorecido políticas contra la violencia.

- Por último, se destaca la gran diferencia que en la práctica existe en la implementación de las políticas en cada Estado, fruto de diferenciales voluntades políticas, distintas instituciones, así como diferentes transposiciones de las directivas europeas.

Otros estudios señalan otras dinámicas en las políticas europeas. Por ejemplo, la «reconciliación» entre la vida laboral y familiar gradualmente habría pasado de un contexto de género - dirigido a compartir las responsabilidades familiares entre hombres y mujeres - a convertirse en un objetivo con orientación al mercado, al promover formas flexibles de empleo (Stratigaki, 2004).

Además de estas cuestiones, se observa en el caso europeo una desviación que implica la relajación de los compromisos en materia de género por un 
cambio en las prioridades, fruto de la crisis económica. Esta laxitud se suma al mayor impacto en las mujeres de las medidas de austeridad que recortan la inversión y el empleo público, si bien la crisis de empleo habría hecho mella en mayor medida en sectores masculinizados (Karamessini y Rubery, 2013).

La promoción de las políticas de igualdad en el empleo se relaciona, por otro lado, en países como España, con la necesidad de afrontar el envejecimiento demográfico (Verloo et al., 2004). Igualmente, en el caso de Reino Unido, las posibles políticas con perspectiva de género (women's friendly policies) terminaron por no serlo, continuando como family-friendly policies (Squires y Wickham-Jones, 2002). Otras investigaciones ofrecen, no obstante, resultados más optimistas para algunos países, como sería el caso de Alemania: como efecto de la europeización, sus políticas de empleo sí habrían incorporado la perspectiva de género (Liebert, 2003).

Finalizando esta contextualización, cabe incidir en las grandes diferencias entre países detectadas en la literatura, divergencias que exigen un análisis, caso por caso, frente a las críticas generales, ya que sí se encuentran experiencias exitosas. Podrían observarse países con una tradición de políticas de carácter transformador, como Dinamarca u Holanda, frente a países entre los que se encontrarían algunos mediterráneos y Reino Unido, que se han caracterizado por aplicar una perspectiva limitada (Rubery et al., 2002).

Además de las problemáticas derivadas del dilema Wollstonecraft en materia de empleo, cabe señalar la dimensión interna del trabajo en organizaciones genderizadas (Acker, 1990) como una problemática de difícil acceso para las políticas públicas, con sus normas explícitas e implícitas en torno al género y a quienes actúan en ese contexto. En este sentido, situándose en el marco de la igualdad de oportunidades en el empleo, procede destacar el impulso europeo a la promoción de políticas de responsabilidad social empresarial o corporativa desde el año 2000 (Comisión Europea, 2001; 2011). Su foco, centrado en acciones voluntarias en el nivel organizacional y especialmente empresarial, así como su elenco de nuevas herramientas, ofrece diversas posibilidades para las políticas de género (Grosser y Moon, 2005; Otero-Hermida, 2009). Destaca el desarrollo de planes de igualdad en el seno de las empresas o el de acciones públicas que valoren el esfuerzo organizacional, como las cláusulas sociales en la contratación y subvenciones públicas en las que se puntúe positivamente el trabajo en materia de igualdad de empresas y otras organizaciones.

En el caso de las políticas de empleo y mainstreaming de género, la RSC sumaría a las tradicionales políticas de igualdad mediante regulación un marco para la promoción voluntaria de distintas prácticas en las empresas, que podrían ser premiadas mediante el consumo público y privado responsable, entre otros.

Muchos de los aspectos citados encuentran una especial relevancia para el ámbito local, especialmente su enfoque a la gestión de los grupos de interés, 
tanto en la definición de los problemas como en la gestión de las políticas en sí. A la importancia de la gestión de la participación en el ámbito local, se sumarían la frecuente falta de recursos y la falta de competencias/agencias del ámbito local en materia de empleo, por lo cual la promoción de iniciativas soft - no necesariamente coercitivas - acoge interesantes puntos de vista en estos ámbitos administrativos, incidiendo sobre aspectos de las culturas de género de forma más accesible que otras Administraciones. Las políticas europeas y estatales respaldarían la intervención local en estos ámbitos a través de los marcos competenciales desarrollados.

\section{POLÍTICAS DE IGUALDAD Y DE EMPLEO EN ESPAÑA: CONTEXTO ESTATAL Y AUTONÓMICO}

En relación al desarrollo de políticas de igualdad, España ha implementado la secuencia enunciada por Walby (2005), partiendo de la estrategia de la igualdad de oportunidades en la década de los años ochenta del siglo Xx, para continuar con enfoques más cercanos a acción positiva en la década de los noventa, y finalmente a partir del año 2000, comenzar el trabajo asociado a la estrategia mainstreaming (Astelarra, 2005). Inicialmente, la institucionalización de las políticas de igualdad se desarrolló bajo el marco del isomorfismo institucional (Alonso, 2008), término referido a la escasa innovación y ausencia de desarrollo de modelos propios en el autogobierno regional frente al modelo estatal (DiMaggio y Powell, 2005). El isomorfismo alcanzaba también a los principales instrumentos de las políticas de igualdad, reproduciéndose los principales objetivos y prioridades en los planes de igualdad, instrumento clave de las políticas en España desde los años noventa. A comienzos del siglo XXI sin embargo se observa un cambio de tendencia que conduce a la sustitución de las fuentes estatales por referencias a instrumentos y mandato europeo, así como a la iniciativa de las CC. AA en materia de legislación en igualdad, avanzando en algunos casos notablemente sobre lo generado en el ámbito estatal (Alonso, 2008).

Con respecto al ámbito municipal, el desarrollo en las últimas décadas ha convertido a las políticas de género en un subsistema de políticas públicas donde el cariz multinivel de su elaboración e implementación adquiere especial relevancia (Subirats y Gomá, 1998). Los municipios se incorporan al esquema multinivel en los años ochenta, con las primeras políticas de promoción de la mujer sustentadas sobre una visión de la mujer como sujeto susceptible de exclusión social (Sampedro, 1992; Giráldez, 2004). Desde entonces, las políticas municipales en materia de género se han institucionalizado y han evolucionado. La mayoría de ayuntamientos contaría con prácticas de igualdad y 
organismos específicos dedicados a ello — aspecto resaltado como crucial por los diferentes estudios de políticas de género en el ámbito local—, si bien la práctica de una visión transformadora de las políticas vinculada a la estrategia mainstreaming sería más limitada según datos que arrojan estudios realizados en Cataluña y Galicia (Gelambí, 2005; Paleo, 2015).

A partir del ańo 2007, con la publicación de la Ley de Igualdad entre Mujeres y Hombres 3/2007, de 22 de marzo, se reconoce la plena competencia de los municipios en materia de igualdad — reconocida como voluntaria en las leyes de régimen local previas-, así como se obliga a su trabajo desde un punto de vista transversal a través de la perspectiva mainstreaming, como cualquier otra Administración pública.

La ley destacó el rol municipal en el desarrollo de planes de usos de los tiempos, dirigidos a armonizar horarios de centros escolares, centros de cuidados, comercio e industria locales y pactos con la comunidad, en pos de un mayor equilibrio en el disfrute de trabajo, ocio y responsabilidades familiares. Dicha ley, en línea con la promoción de la responsabilidad social en las empresas, estableció la obligatoriedad de realizar planes de igualdad para aquellas empresas de más de 250 trabajadores, siendo voluntarios para las pymes.

Igualmente, las comunidades, a través de sus leyes de igualdad propias, han actuado a través de diferentes enfoques: aquellas comunidades que proponen áreas de intervención concretas para el ámbito local han destacado de forma especial la conciliación, seguida de prioridades como la participación, el empleo o la sensibilización; por otro lado, en cuanto a elementos específicos de igualdad en el empleo, algunas comunidades, como Castilla y León, han reconocido competencia municipal en la materia; otras han configurado genéricamente la participación de las entidades locales en las políticas de empleo en igualdad, y algunas, como Galicia, han desarrollado normativa propia sobre trabajo e igualdad que sitúa el rol local claramente en el ámbito de los usos del tiempo (Otero-Hermida, 2016).

Respecto al papel que los municipios se atribuyen en cuestiones relacionadas con el empleo, es de interés el impacto de la European Charter for Equality of Women and Men in Local Life — desarrollada por una extensa agrupación de municipios europeos- desde diversos planos: rol del municipio como empleador; trabajo y conciliación; introducción de cláusulas sociales de género en la contratación pública; búsqueda de ratios equilibradas de empleo y calidad en el empleo; impulso del emprendimiento femenino; fomento empresarial de la igualdad, o promoción de ocupaciones menos feminizadas y menos masculinizadas.

Asimismo, cabe destacar la impronta de los proyectos auspiciados por la iniciativa comunitaria EQUAL, con gran participación de los municipios 
españoles, en la promoción de los pactos locales por la igualdad en el empleo, materializados en el desarrollo de foros permanentes de observación y debate en torno a la situación de la igualdad en el empleo de los municipios. Se trata de una adaptación de las políticas de igualdad a la promoción de los pactos locales por el empleo, en los que se han observado notables sesgos de género debido a la escasa participación de asociaciones de mujeres u organismos de igualdad (Carballada et al., 2005).

Con el estallido de la Gran Recesión, la destrucción de empleo mayoritariamente masculino ha acercado las ratios de desempleo de ambos sexos, pero, mientras los hombres han empeorado en términos relativos, las mujeres siguen exhibiendo una tasa de paro superior a la media, permaneciendo en desventaja en términos absolutos. A este oscuro panorama habría que ańadir el hecho de que la brecha de género existente es mayor que en otros países de la OCDE, con menores tasas de empleo femeninas y una menor red de cuidados, entre otras formas de desigualdad (Cooke, 2009). E, igualmente, la actividad laboral se desarrolla en circunstancias laborales más precarias y endurecidas, generando mayor pobreza en las mujeres (Unión General de Trabajadores, 2015).

En el contexto general de «desmantelamiento» de las políticas de género (Lombardo y León, 2015), el empobrecimiento de las políticas de empleo no ha sido complementado con un tratamiento compensador a través de políticas sociales. El mainstreaming ha fallado, observándose políticas compartimentadas que han sido abandonadas y una constricción de los derechos de las mujeres a través de normativas como la propuesta de ley del aborto (Lombardo y León, 2015).

Esto se habría acompañado de una desarticulación de las instituciones de igualdad, observándose cómo desaparecían instituciones autonómicas, así como consejos de Participación de la Mujer — por ejemplo, en Galicia y Madrid (Alonso y Paleo, 2014; Diz y Lois, 2011)—. Igualmente, han aflorado casos de uso perverso de algún instrumento de la política, como pone en evidencia, por ejemplo, la utilización de informes de género para justificar la reducción del Fondo Municipal de Empleo en 2010, aduciendo un mayor impacto en los hombres (Ruiz, 2012).

En general, la literatura coincide en que, tras la consolidación de la protección social, siguiendo las directrices europeas, los pasos de las políticas activas de empleo se han encaminado a la flexibilidad del mercado de trabajo (Díaz et al., 2004; Miguélez et al., 1999; Miguélez, 2004; Prieto y Miguélez, 2009; Ruiz, 2004; Tobes, 2002). Sus actores se han ampliado más allá de patronal, sindicatos y servicios públicos estatal y autonómicos, pues otras Administraciones de menor nivel, así como entidades sin ánimo de lucro, se han involucrado en la ejecución de estas actividades. 
En este plano general de políticas de empleo, el foco de las medidas de igualdad ha estado más centrado en la promoción de más igualdad en el ámbito productivo que en aquellas iniciativas que podían generar más igualdad en el ámbito privado, según se desprende del análisis de planes regionales y estatales (Bustelo, 1999; 2004; Heras, 2006; Carrasco, 2001).

Nuevamente, desde un punto de vista supralocal, pero en el contexto de la recesión, las políticas de austeridad habrían tenido su cuota de impacto en el ámbito local no solo en términos de reducción presupuestaria, sino también de recorte competencial amparado en la Ley 27/2013, de 27 de diciembre, de Racionalización y Sostenibilidad de la Administración Local. En materia de políticas de género, dicha ley puede comprometer gravemente las políticas, especialmente aquellas más relacionadas con servicios sociales, entre otros motivos por el desajuste entre las crecientes competencias asumidas por los ayuntamientos y la previsión de financiación que podría materializar la ejecución de dichas competencias (Roldán y Leyva, 2014).

A continuación se presentan datos relativos a la igualdad/desigualdad de género en el mercado laboral español en los años de inicio del desarrollo de la crisis, previos al desmantelamiento de las políticas de igualdad.

Tabla 1. Perfil de desigualdad y mercado laboral en España previo al desmantelamiento de las politicas de igualdad

\begin{tabular}{|c|c|}
\hline Acceso al empleo & $\begin{array}{l}\text { Tasa de paro: Mujeres, 11,1\%; hombres, 6,9\% } \\
\text { (INE, 2008). } \\
\text { Segregación horizontal: El 25,4\% de la ocupación en la } \\
\text { industria o el escaso 5,68 en el sector de la construcción son } \\
\text { mujeres, mientras el 52,94\% de los ocupados en servicios } \\
\text { son mujeres, en especial en las áreas educativas de atención y } \\
\text { hostelería. Esta tendencia, lejos de disminuir, aumentó en la } \\
\text { mayoría de países europeos, también en España (Comisión } \\
\text { Europea, 2008). }\end{array}$ \\
\hline Promoción & $\begin{array}{l}\text { Segregación vertical: La proporción de mujeres managers en } \\
\text { España es de un } 31,8 \% \text {, frente al casi } 70 \% \text { de hombres } \\
\text { (Comisión Europea, 2008). En el caso de mujeres miembro } \\
\text { de consejos de administración en empresas del IBEX35, la } \\
\text { cifra baja hasta el } 6 \% \text { en 2007, frente al } 5,1 \% \text { en } 2006 \text {, con } \\
\text { una mejora respecto a 2005, donde eran en torno a un } 3 \% \\
\text { (CNMV, 2008). }\end{array}$ \\
\hline Retribución & $\begin{array}{l}\text { Las mujeres perciben alrededor de un } 20 \% \text { menos de salario } \\
\text { (Instituto de la Mujer, 2007). }\end{array}$ \\
\hline
\end{tabular}




\begin{tabular}{|c|c|}
\hline $\begin{array}{l}\text { Condiciones } \\
\text { laborales }\end{array}$ & $\begin{array}{l}\text { Contratos a tiempo parcial: El 80,4\% de los trabajadores } \\
\text { a tiempo parcial eran mujeres (INE, 2008). La jornada a } \\
\text { tiempo parcial implica una menor cotización, así como puede } \\
\text { suponer una menor posibilidad de formación, menores } \\
\text { opciones de promoción, entre otras posibles consecuencias. } \\
\text { Temporalidad: España es el país con mayor tasa de } \\
\text { temporalidad en los contratos de los } 27 \text { miembros de la } \\
\text { Unión Europea (Comisión Europea, 2008). Las mujeres } \\
\text { cuentan con un 4,3\% más de contratos temporales. }\end{array}$ \\
\hline $\begin{array}{c}\text { Conciliación/ } \\
\text { Corresponsabilidad }\end{array}$ & $\begin{array}{l}\text { En España, en 2006, el 58,8\% de las mujeres (en edades } \\
\text { comprendidas entre los } 25 \text { y } 49 \text { años) con hijos a su cargo } \\
\text { tenía un trabajo remunerado, frente a un } 93,2 \% \text { de hombres } \\
\text { en situación similar (Comisión Europea, 2008). } \\
\text { El } 96 \% \text { de las personas que en España no buscan empleo por } \\
\text { razones familiares son mujeres (INE, 2008) } \\
\text { Las mujeres españolas dedican cada día tres horas más que los } \\
\text { hombres a tareas relacionadas con el hogar y la familia (INE, } \\
\text { 2003). }\end{array}$ \\
\hline
\end{tabular}

Fuente: elaboración propia.

\section{MÉTODO}

Para llevar a cabo este estudio (acciones y rol local en materia de igualdad en el empleo en España) se seleccionó un universo de 237 municipios de mediano tamaño (entre 25000 y 100000 habitantes) para los que se elaboró un cuestionario dirigido a la persona responsable del área de igualdad.

La elección del universo respondía al predominio en España de municipios de menor tamaño frente a otros países del entorno (Vallés y Brugué, 2001). Estudios previos indicaban la gran diferencia de este segmento de municipios respecto a las poblaciones más grandes, por otro lado estudiadas habitualmente a través de estudios de caso, y a las menores de 25000 habitantes, cuyas acciones en la materia son escasas (Roldán, 2004).

La muestra final de la encuesta fue de 198 municipios, lo que supuso el $84 \%$ del universo [ $95,5 \%$ dos sigmas, $\mathrm{p}=\mathrm{q}$, error muestral $\pm 2,24 \%$ ], observándose proporcionalidad respecto al universo en las variables independientes —nivel gerencial del organismo de igualdad (Roldán, 2004; Gelambí, 2005); afiliación política y sexo de quien ostenta la alcaldía (Tobes y Angoitia, 2005), y disponibilidad de un plan de igualdad municipal - y de control planteadas: el tamaño del municipio — para asegurar la proporcionalidad de la muestray la relación esfuerzo/apoyo por parte de otras Administraciones, cuestión 
fundamental dadas las características del sistema local español, donde se ha observado una alta dependencia financiera de instituciones supramunicipales (Sellers y Lidström, 2007).

El cuestionario inquiría sobre temas como la representación femenina en el municipio, las estructuras de igualdad y servicios a mujeres, el uso de instrumentos de mainstreaming, el nivel y tipo de apoyo externo recibido, así como las políticas de empleo desarrolladas. Para ello, se realizó un exhaustivo análisis de la literatura existente en materia de igualdad en el empleo en el ámbito local español y se elaboró previamente un amplio catálogo de posibles acciones derivadas del análisis documental anteriormente citado, complementado con el análisis de planes locales de igualdad, literatura gris e informes (Alfama y Quintana, 2007) y materiales didácticos emitidos por autoridades públicas destinados a municipios (materiales europeos, autonómicos y de la Federación Española de Municipios y Provincias).

Tras la administración del cuestionario, se prosiguió por una vía cualitativa, a través de la selección de cuatro estudios de caso - tabla 2-, en función del nivel de apoyo recibido desde entidades supramunicipales - a través de asesoría, financiación u otros-y el grado de esfuerzo realizado, examinado a partir de aspectos como la dedicación de presupuesto, el uso de instrumentos de mainstreaming (desagregación estadística, planes de igualdad, cláusulas sociales, uso de instrumentos de participación o sensibilización). Se partió de una selección propia de instrumentos (existencia de oferta de servicios para mujeres, direccionamiento de las políticas de empleo a distintos públicos objetivo) adaptados al entorno local a partir del trabajo de Alonso (2012).

Tabla 2. Casos de estudio

\begin{tabular}{ll}
\hline \multicolumn{1}{c}{ Cuadrante 1 } & \multicolumn{1}{c}{ Cuadrante 2 } \\
\hline $\begin{array}{l}\text { Contexto favorable (apoyo recibido) y } \\
\text { esfuerzo municipal escaso en politicas de } \\
\text { igualdad de género en el empleo }[+/ \text {-] }\end{array}$ & $\begin{array}{l}\text { Contexto favorable (apoyo recibido) y } \\
\text { esfuerzo municipal elevado en politicas de } \\
\text { igualdad de género en el empleo }[+ \text { I +] }\end{array}$ \\
\hline Caso seleccionado: & Caso seleccionado: MOLLET DEL V \\
ALMENDRALEJO (BADAJOZ) & ALLES (BARCELONA) \\
\hline \multicolumn{1}{c}{ Cuadrante 3 } & \multicolumn{1}{c}{ Cuadrante 4 } \\
\hline Contexto desfavorable (apoyo recibido) y & Contexto desfavorable (apoyo recibido) y \\
esfuerzo municipal escaso en politicas de & esfuerzo municipal elevado en politicas de \\
igualdad de género en el empleo [ - I -] & igualdad de género en el empleo [ - I +] \\
\hline Caso seleccionado: & Caso seleccionado: \\
JÁVEA /XÀBIA (ALICANTE) & CIEZA (MURCIA) \\
\hline
\end{tabular}

Fuente: elaboración propia. 
Los casos fueron estudiados en profundidad a través de la revisión de material documental sobre planes de igualdad y programas de empleo, así como a través de la realización de diez entrevistas semiestructuradas a asociaciones de mujeres, personal político y técnico del área de igualdad y de los centros municipales dedicados a empleo.

\section{RESULTADOS DEL CUESTIONARIO}

\section{INSTRUMENTOS GENERALES DE MAINSTREAMING}

Respecto al uso de instrumentos de mainstreaming, que, de forma amplia, sin necesariamente ser aplicados a las políticas de empleo, pueden reforzar las mismas, los datos recabados retratan la existencia de una voluntad de desarrollar una arquitectura municipal que sostenga las políticas de igualdad de género, lastrada por la carencia de recursos que deberían asentar las estructuras municipales creadas a tal efecto y garantizar la implementación adecuada de programas: por un lado, la mayoría de municipios $(58,7 \%)$ contaba con un organismo de participación para asociaciones de mujeres e igualdad (Consejo de la Mujer) y con un plan de igualdad municipal $(54 \%)$, dotado de presupuesto propio $(70,3 \%)$. Sin embargo, con porcentajes elevados se declaraba no usar, en ningún caso, la desagregación de datos por sexos $(70 \%)$ o no utilizar $(67,7 \%)$ informes de impacto de género en las políticas. Se observa un importante desarrollo de la participación, si bien cuestiones como la recogida de datos y la valoración de impacto de género no son aspectos normalizados, afectando al diseño y evaluación de las políticas.

En la misma tónica, solo el 8,1\% de los municipios incluía regularmente cláusulas de género en los pliegos de contratación municipales; el 33\% las aplicaba de forma ocasional y el $23,7 \%$ solo las consideraba al contemplar la concesión de subvenciones.

En lo que concierne a las políticas de empleo, en concreto, pese a que las estructuras municipales de igualdad dedican un esfuerzo importante a la igualdad en el empleo, se constata que no parecen integrar estas cuestiones en el uso normalizado de instrumentos de mainstreaming como los planes de igualdad —el 80,9\% de los municipios no contaba con partidas específicas para la igualdad en el empleo en sus planes de igualdad y, un 38,4\% no destinaba presupuesto para tal fin-o en la colaboración con otras áreas en la materia a nivel financiero. La cantidad media presupuestada para la igualdad en el empleo asciende a 60000 euros anuales, proviniendo los fondos tanto del propio organismo de igualdad $(49,5 \%)$ como de otras áreas municipales $(42,9 \%$,$) .$ 
De forma global, los datos recabados muestran una débil instrumentalización de la estrategia mainstreaming, observándose graves barreras a la integración de la perspectiva de género en las políticas, como es el caso de la escasez del análisis de género o los déficits en la planificación financiera que permite la ejecución final de acciones efectivas.

\section{MEDIDAS GENERALES POR LA IGUALDAD EN EL EMPLEO}

La observación previa sobre la existencia de una incipiente voluntad de creación de estructuras facilitadoras de la institucionalización de las políticas de igualdad de género, acompañadas, sin embargo, de un escaso compromiso de dotación de recursos, se refrenda al comprobar las medidas adoptadas en materia de igualdad en el empleo, en particular.

Respecto a los Pactos por la Igualdad en el empleo o foros de debate similares entre distintos actores de las políticas de igualdad y de empleo en el municipio, se observa que su uso es anecdótico — solo en el 5,6\% disponía de un pacto, cuya antigüedad media rondaba los 4,25 años-. En los escasos casos existentes, se pone en evidencia que un tercio de los pactos carecía de participación de asociaciones de mujeres o igualdad, poniendo, en cambio, el acento en la participación de sindicatos y empresas. La usencia de desarrollo de estos pactos limita el potencial participativo de una estrategia mainstreaming para el empleo en los municipios, así como el debate y la detección temprana de problemáticas.

Aunque las estructuras municipales de atención específicas para mujeres dedican elevados recursos a la orientación laboral, existente en la mayoría de municipios $(70,3 \%)$, muy pocos $(12,1 \%)$ acompañan esta oferta con servicios de apoyo al cuidado que permitan disfrutar de estos servicios. Otro tipo de acciones son escasamente emprendidas, como la disposición de planes municipales de usos de los tiempos $(7,1 \%)$, siendo, sin embargo, una de las principales contribuciones posibles de los municipios dispuesta por la normativa supramunicipal, como se detalló anteriormente.

\section{ACCIONES ESPECÍFICAS POR LA IGUALDAD EN EL EMPLEO}

El cuestionario empleado indagaba acerca de las políticas de empleo, independientemente de las estructuras de igualdad, observando acciones desarrolladas en el marco de las políticas de empleo municipales según público objetivo (tabla 3). Según se ha comprobado, las acciones se destinaban fundamentalmente a la promoción del emprendimiento y a las personas desempleadas, mientras que las acciones dirigidas a la Administración pública como empleadora, así como al área rural, fueron menos frecuentes. 
Tabla 3. Públicos objetivo de las acciones municipales en materia de empleo

\begin{tabular}{lc}
\hline \multicolumn{1}{c}{ Públicos objetivo } & $\begin{array}{c}\text { Municipios que realizan acciones } \\
\text { destinadas a cada público (\%) }\end{array}$ \\
\hline Futuros/as empresarios/as & $62,1 \%$ \\
\hline Personas inactivas/desempleadas & $60,0 \%$ \\
\hline Personas trabajadoras & $48,0 \%$ \\
\hline Mandos de empresas & $40,4 \%$ \\
\hline Administración pública municipal & $34,3 \%$ \\
\hline Área rural & $16,2 \%$ \\
\hline Otros & $3,0 \%$ \\
\hline
\end{tabular}

Fuente: elaboración propia.

Observando el foco de acción de las políticas según público objetivo se pueden intuir algunos de los déficits en las políticas de empleo a nivel europeo citadas en la revisión de la literatura, centrándose el foco en la incorporación de las mujeres al mercado por cuenta ajena o propia, si bien en menor medida se incide en los entornos de trabajo tras su incorporación.

En los subapartados siguientes se expone información, sobre las principales acciones realizadas por los municipios en materia de igualdad en el empleo, el grado de satisfacción cosechado y la antigüedad media en su desarrollo, así como el grado de participación en las mismas del organismo público de mujer/igualdad, y la participación de otras organizaciones como sindicatos, organizaciones empresariales y empresas y asociaciones que persiguen la igualdad de género entre sus objetivos. Es decir, se ha pretendido observar, además de qué acciones se realizaban, qué actores teóricamente implicados en las políticas de igualdad en el empleo lo estaban finalmente en las acciones desarrolladas, dado que mainstreaming supone incorporar la perspectiva de género contando con los actores normalmente implicados en las políticas, en este caso en la de empleo a nivel municipal.

\subsection{Actuaciones dirigidas a la Administración pública local en el ámbito del empleo}

Las principales actuaciones dirigidas a la Administración pública local (tabla 4) fueron la realización de estudios específicos de género en el área local $(72,7 \%)$ y la promoción de la formación en género de los servicios de empleo municipales (70,5\%). Tras estas cabe destacar también el impulso de los 


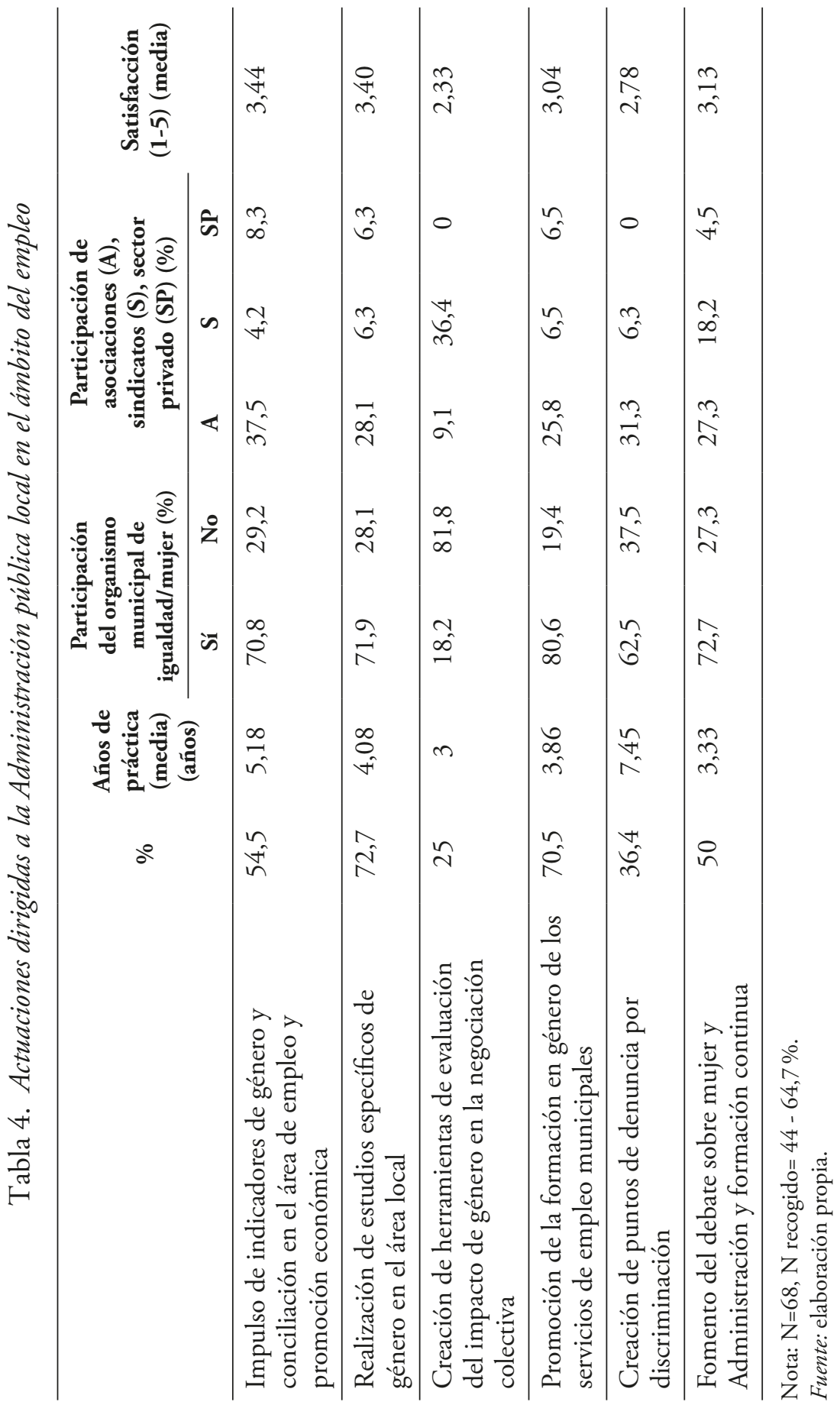


indicadores de género y conciliación en los diagnósticos previos a programas y proyectos de la Administración local en materia de empleo y promoción económica $(54,5 \%)$ y el fomento del debate y la formación en el seno administrativo $(50 \%)$. Entre los municipios examinados, las actuaciones menos frecuentes fueron la creación de puntos de denuncia por discriminación y herramientas de evaluación del impacto de género en la negociación colectiva (36,4\% y 25\%, respectivamente).

A pesar de ser una de las actuaciones menos frecuentes, la creación de puntos de denuncia por discriminación es la acción que lleva más tiempo en funcionamiento en estos municipios, superando los 7 ańos de media (7,45 años).

La participación del organismo municipal de la mujer —u órgano análogo- resulta más habitual en actuaciones como la promoción de la formación en género de los servicios de empleo municipales $(80,6 \%)$, el fomento del debate y la formación en el seno administrativo $(72,7 \%)$, la realización de estudios $(71,9 \%)$ y el impulso de los indicadores de género y conciliación en los diagnósticos previos a programas y proyectos de empleo y promoción económica $(70,8 \%)$. Se observa, por tanto, cierta colaboración en el ámbito más interno en relación a las políticas de igualdad en el empleo dirigidas a la propia Administración, si bien es una actividad globalmente poco desarrollada, como se citaba. La participación de asociaciones y otros actores externos como sindicatos es menor, destacando su colaboración en el impulso de indicadores $(37,5 \%)$ y en la creación de puntos de denuncia por discriminación $(31,3 \%)$, si bien el sector privado muestra un escaso nivel participativo en estas actuaciones. El desarrollo de indicadores de género en las políticas de empleo se observa de especial interés dada la capacidad municipal de detección periódica de problemáticas derivada de su proximidad, así como se valora su desarrollo en colaboración con otros actores.

En cuanto al grado de satisfacción de los entrevistados con su funcionamiento, cuatro de las seis actuaciones obtienen una puntuación media superior al 3 en una escala del 1 al 5 , siendo peor puntuadas las actividades menos frecuentes.

\subsection{Actuaciones dirigidas a personas inactivas o desempleadas}

Entre las actuaciones dirigidas a personas inactivas o desempleadas (tabla 5) —las más habituales de las realizadas en materia de políticas de empleo con perspectiva de género-, fueron la formación ocupacional y el acompañamiento a la inserción laboral de las mujeres, ejecutados en el 86,1\% de estos municipios, así como las acciones de promoción y formación en el empleo de mujeres víctimas de violencia de género $(73,4 \%)$, los talleres de motivación y autoafirmación para mujeres inactivas $(70,9 \%)$ y aquellas dirigidas a mujeres inmigrantes $(67,1 \%)$. 


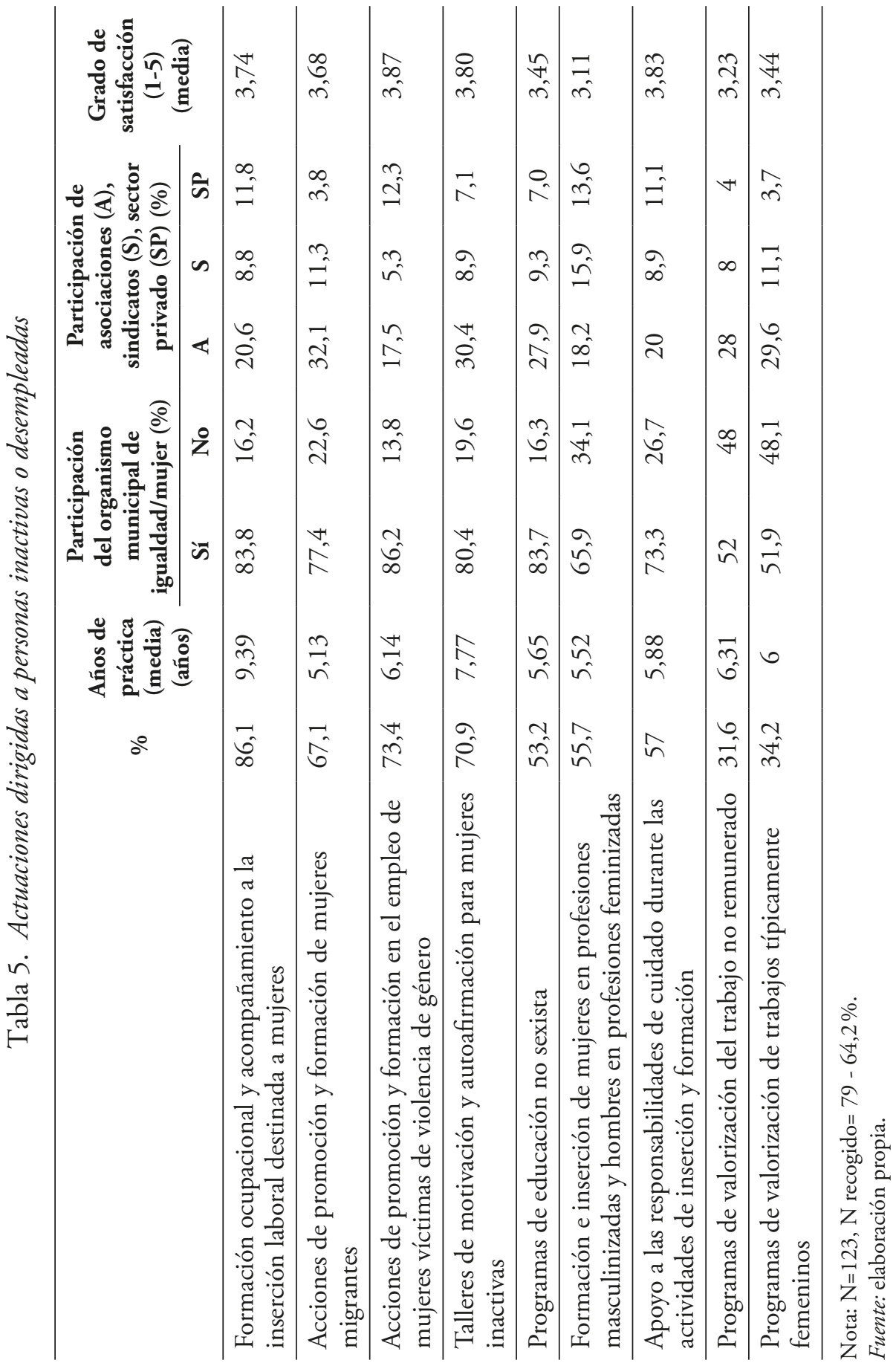


Las actuaciones menos habituales son las que pretenden la valorización del trabajo no remunerado de la mujer $(31,6 \%)$ y del trabajo típicamente femenino $(34,2 \%)$. En este sentido, se observa claramente el sesgo detectado en el marco europeo de las políticas de empleo citado previamente: la problemática se centra en la incorporación de la mujer al empleo normalizado, asociado a mayor remuneración y valoración social, mientras las esferas tradicionalmente femeninas, tanto remuneradas como no remuneradas, están más lejos del foco de la política, también en los municipios.

La actuación más habitual de este bloque, la formación ocupacional y el acompańamiento a la inserción laboral de la mujer, es también la que cuenta con mayor tiempo de existencia media ( 9,39 años). Sin embargo se observa una tendencia positiva a otro posible foco en las políticas, ya que las acciones que se han iniciado más recientemente son el apoyo a las responsabilidades de cuidado durante las actividades de inserción y formación, los programas de educación no sexista, la formación e inserción de mujeres en profesiones masculinizadas y de hombres en profesiones feminizadas, y el apoyo mujeres inmigrantes, observándose en este último caso la aparición de la perspectiva de género interseccional, es decir, que reconoce las interacciones diferenciales del género con otras variables de diversidad, como el origen étnico, el estrato socioeconómico o la edad.

La participación del organismo municipal de igualdad alcanza sus mayores cotas en las acciones destinadas a la promoción y formación en el empleo de colectivos de mujeres víctimas de violencia de género, la formación ocupacional y el acompañamiento a la inserción laboral de mujeres, los programas de educación no sexista y los talleres de motivación y autoafirmación para mujeres inactivas laboralmente, todas ellas con porcentajes de respuesta positiva superiores al $80 \%$.

En las actuaciones de este bloque se observa también una mayor participación de las asociaciones que de sindicatos o sector privado, pues en todas ellas el porcentaje de respuesta de aquellas es el mayoritario. Dicho porcentaje alcanza sus valores más elevados en las acciones de promoción y formación en el empleo de mujeres inmigrantes $(32,1 \%)$, los talleres de motivación y autoafirmación para mujeres inactivas $(30,4 \%)$ y los programas de valorización de trabajos típicamente femeninos $(29,6 \%)$.

Aunque los sindicatos y el sector privado muestran porcentajes mucho menores, se advierte que la presencia del sector privado es mayor que la de los sindicatos en la formación ocupacional y acompañamiento a la inserción laboral de las mujeres (11,8\% frente al 8,8\%), en la promoción y formación de víctimas de violencia de género $(12,3 \%$ frente al $5,3 \%)$ y en el apoyo a las responsabilidades de cuidado durante la inserción y formación (11,1\% frente al 8,9\%). 
Todas las actuaciones del presente bloque obtienen una puntuación superior al 3, alcanzando su valor más alto en las acciones de promoción y formación en el empleo de mujeres víctimas de violencia de género - 3,87- y el más bajo, en la formación e inserción de mujeres en profesiones masculinizadas y de hombres en profesiones feminizadas $(3,11)$. La segregación sexual por sectores es una de las fuentes de desigualdad más habituales, así como una de las cuestiones que menos evolucionaban según se indicaba en la tabla 1 , lo cual, sumado a esta baja satisfacción, sitúa la problemática en el foco de futuras políticas.

\subsection{Actuaciones dirigidas a trabajadoras y trabajadores}

Del conjunto de actuaciones dirigidas a trabajadoras y trabajadores (tabla 6), las más habituales en los municipios examinados son las relacionadas con la formación en igualdad de oportunidades $(74,6 \%)$ y el apoyo a las responsabilidades familiares de las trabajadoras y trabajadores $(61 \%)$.

En cuanto a ańos de experiencia, la oferta de puntos de apoyo para víctimas de acoso sexual en el trabajo es la que muestra mayor tiempo de existencia media, superando los 7 años $(7,85)$. Tras esta, cuentan con más de 6 años de existencia acciones como el apoyo a las responsabilidades familiares de trabajadoras y la formación en igualdad de oportunidades y el apoyo a la emergencia del trabajo sumergido. Entre las actuaciones de más reciente existencia podemos destacar el fomento del teletrabajo (3,60 años), la sensibilización acerca del permiso de paternidad (2,07 años) y la creación de bancos de tiempo (1,33 años).

En la participación del organismo de la mujer u órgano análogo se observan porcentajes muy dispares: los más elevados corresponden a la formación en igualdad de oportunidades $(81,8 \%)$ y a la promoción profesional de mujeres $(80 \%)$.

Respecto a la participación de asociaciones, sindicatos y sector privado en la práctica de estas actuaciones, como en los anteriores bloques, las asociaciones vuelven a ser las más involucradas de forma global, salvo en el caso de apoyo para víctimas de acoso sexual en el trabajo y apoyo a la emergencia del trabajo sumergido, iniciativas en las que los sindicatos alcanzan mayores porcentajes de respuesta. El sector privado muestra su porcentaje de respuesta más elevado en los programas de valorización y formalización de los servicios de cuidado, si bien son bajos porcentajes y en algunas acciones la participación es inexistente.

Las acciones que generaron mayores niveles de satisfacción fueron el apoyo a las responsabilidades familiares $(3,62)$ y los puntos de apoyo para víctimas de acoso sexual en el trabajo $(3,48)$.

La baja participación del sector privado en este campo de las políticas es sin duda un reto dada la necesidad de involucrar a los empleadores para desarrollar 


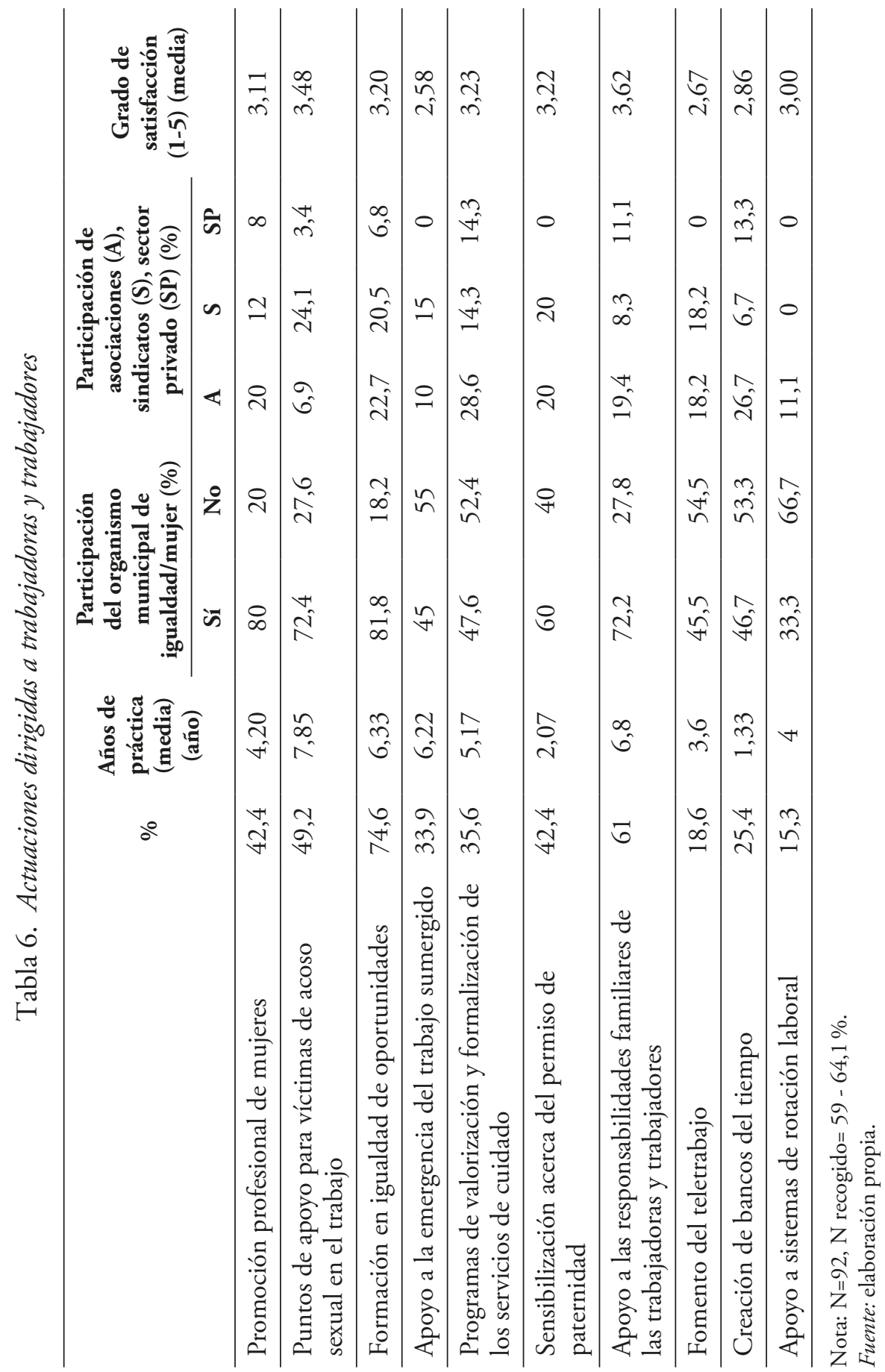


muchas de las acciones estudiadas, muchas de ellas posiblemente desarrolladas en el marco de la responsabilidad social empresarial. Se observan acciones incipientes en materia de usos del tiempo, siendo un aspecto especialmente destacado en la ley de igualdad 2007 para el ámbito municipal.

\subsection{Actuaciones dirigidas a emprendedores/as y promoción empresarial}

En lo que concierne a las iniciativas orientadas al emprendimiento y promoción empresarial (tabla 7), son más habituales las ayudas al autoempleo en las mujeres $(93,4 \%)$ que el fomento de la creación de redes de emprendedoras $(63,9 \%)$, siendo también acciones más antiguas. No existen diferencias notables en el resto de aspectos.

El acento en el autoempleo es otro instrumento disponible para la incorporación de las mujeres al mercado laboral, además del trabajo por cuenta ajena; no es sin embargo acompañado por otras acciones que integren un marco diferencial en dicha incorporación.

\subsection{Actuaciones dirigidas a empresas}

Entre los municipios que practican alguna actuación dirigida a las empresas (tabla 8), las más habituales de las consideradas en este bloque fueron el apoyo a la realización de planes de igualdad en las empresas, en especial en las pymes $(63,3 \%)$, y la sensibilización contra la discriminación femenina en el empleo y el acoso sexual (61,2\%), siendo el fomento del permiso de paternidad la medida menos cultivada.

Solo una de estas actuaciones cuenta con una experiencia superior a los 6 años: es el caso de la sensibilización de género para una mayor atención a colectivos con posibilidad de discriminaciones combinadas.

Igualmente, se observa el impacto de la legislación estatal de igualdad a través de la puesta en marcha de un apoyo a la realización de planes de igualdad en las empresas y el impulso a la creación de la figura del agente de igualdad en la empresa, medidas con una antigüedad que ronda los dos años.

La participación del organismo municipal de la mujer es alta en la mayor parte de actuaciones, si bien muestra sus porcentajes más bajos en el apoyo a la figura del agente de igualdad en la empresa $(31,3 \%)$ y la lucha contra el «techo de cristal» (25\%).

En la práctica de las actuaciones dirigidas a empresas, la participación de los sindicatos es ciertamente importante. Por su parte, las asociaciones participan con mayor intensidad en las acciones de sensibilización de género para mayor atención de colectivos con posibilidad de discriminaciones combinadas $(34,6 \%)$, contra la discriminación femenina $(30 \%)$ y en apoyo a la flexibilidad 

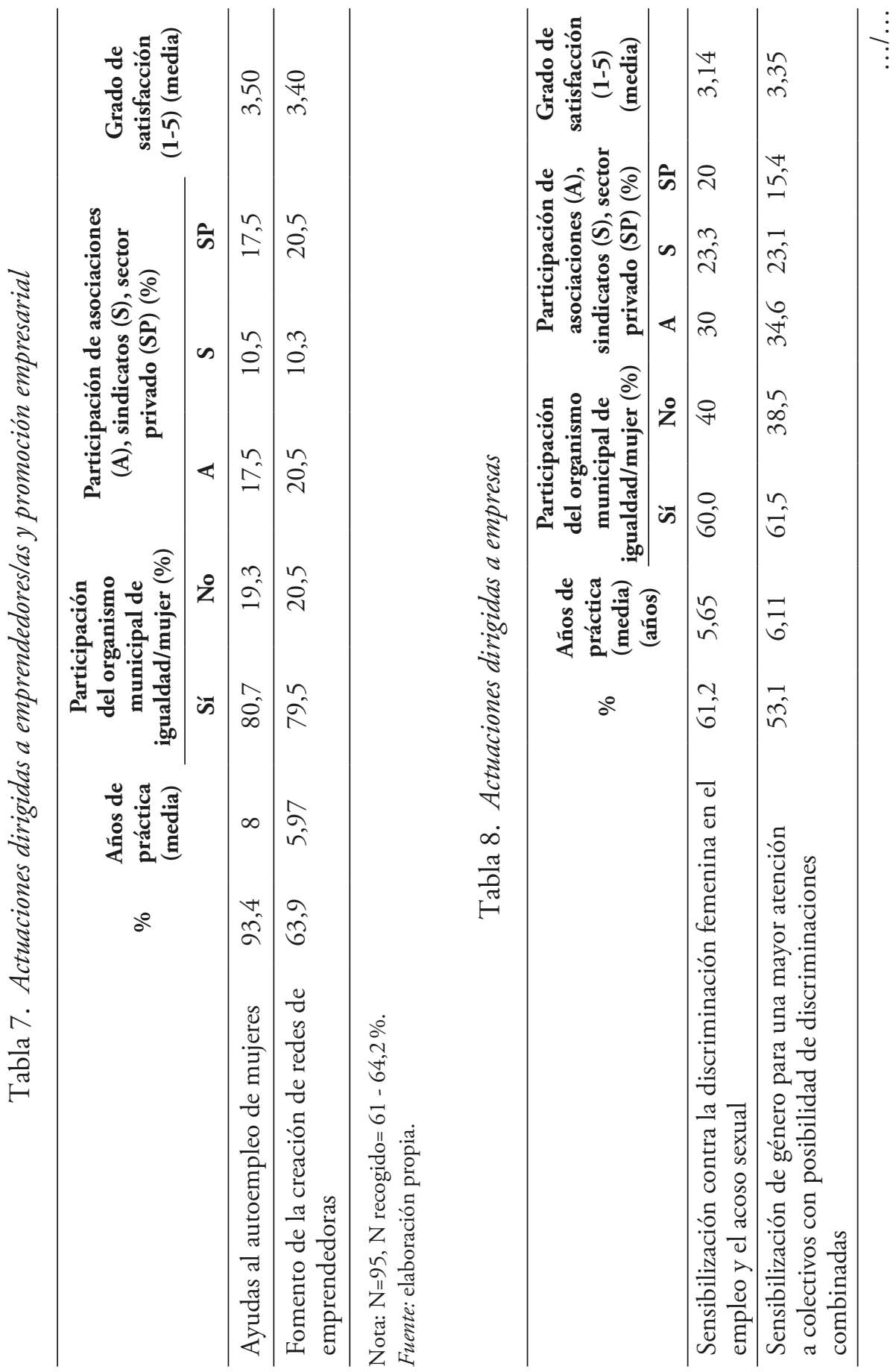


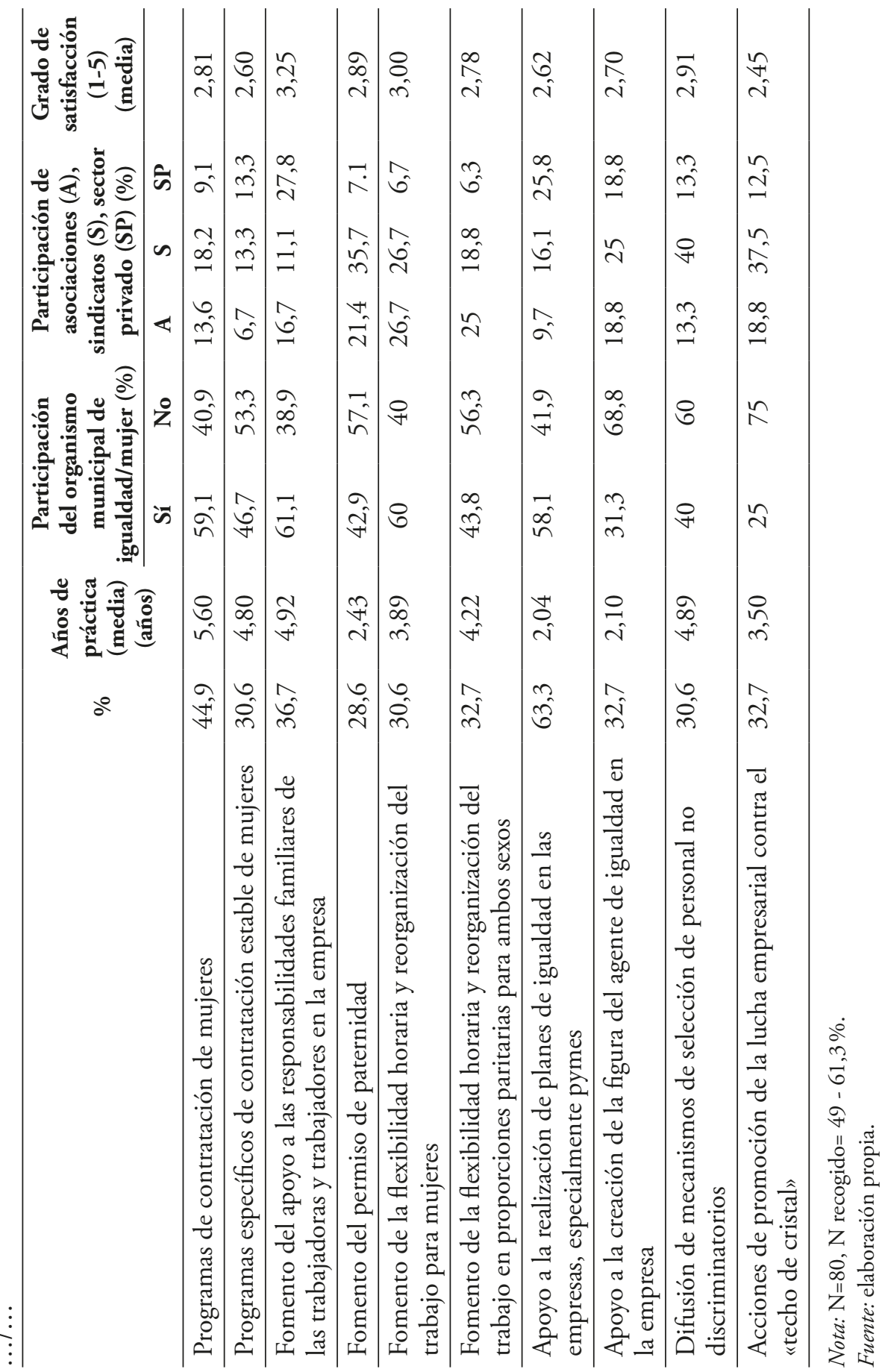


horaria (25\%). El sector privado participa más en el apoyo a las responsabilidades familiares $(27,8 \%)$ y en la realización de planes de igualdad en la empresa $(25,8 \%)$.

La satisfacción no es, sin embargo, muy alta. Solo cuatro actuaciones obtienen un grado medio de satisfacción que alcance o supere el 3: la sensibilización, el fomento del apoyo a las responsabilidades familiares y el fomento de la flexibilidad horaria.

Cabe destacar que el porcentaje de municipios que realizaba acciones dirigidas a este público objetivo sobrepasaba apenas el $40 \%$. Por ello, de forma global las acciones dirigidas al público empresarial deben definirse como escasas. El acento permanece en las personas, frente a acciones dirigidas a las organizaciones en las que se dan las condiciones de empleabilidad y desarrollo del trabajo, si bien es una tendencia creciente a destacar. En particular, el fomento de la elaboración de planes de igualdad es una acción incipiente que comienza a realizarse mayoritariamente en 2007, observándose por tanto el impacto de la legislación de igualdad estatal del mismo año, como se citaba. Este tipo de acciones cuenta con una más alta participación del sector privado, si bien una mayor colaboración podría continuar siendo uno de los grandes retos de la política.

\subsection{Actuaciones dirigidas al área rural}

El último de los bloques de este apartado, referido a las actuaciones dirigidas al área rural (tabla 9), fue el que contó con un mayor porcentaje de respuesta, pese a ser una línea muy poco desarrollada.

Destacan las acciones para la visibilización del trabajo agrícola femenino la copropiedad de explotaciones y la participación de asociaciones de forma general.

\section{HALLAZGOS EN LOS ESTUDIOS DE CASO}

En los cuatro casos estudiados (Jávea, Mollet del Vallès, Almendralejo, Cieza) se observa un completo desarrollo de planes de igualdad, donde se describen y diagnostican necesidades relativas a una gran amplitud de acciones posibles en materia de empleo en igualdad y se pone especial hincapié en la adopción de una perspectiva de corresponsabilidad, cuidado, y en materias no remuneradas.

En la práctica, los municipios concretan sus acciones dirigiéndolas a la mejora de la empleabilidad de las mujeres y su inserción laboral. Uno de los municipios declaraba disponer de una bolsa de empleo exclusivamente 


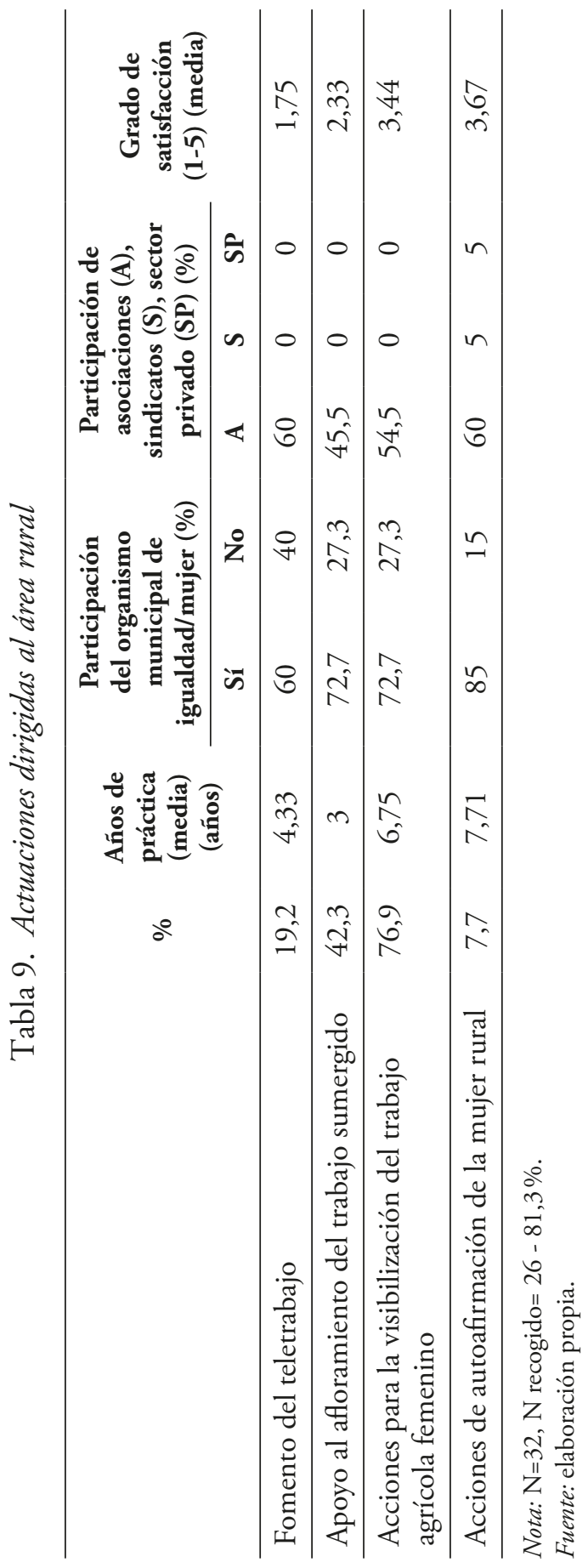


femenina, si bien no parecía una medida que incidiese efectivamente en la contratación final. Otras acciones no se realizaban, alegando falta de presupuesto, a excepción de uno de los casos, donde se observó que su actuación era más transversal, contemplando cláusulas de género en los procedimientos de contratación municipales, sensibilización en materia de corresponsabilidad y apoyo para la realización de planes de igualdad en empresas, así como la oferta de un módulo de género en todos los cursos relacionados con el empleo que el municipio ofrecía a sus distintos públicos, considerado de especial interés.

Los municipios expresaron la crucial importancia del apoyo supramunicipal a la hora de realizar acciones. No obstante, como otra cara de la misma moneda, esa dependencia constituye, igualmente, para los municipios, un obstáculo que condiciona el rango de programas y prestaciones a ofertar.

Las responsables de políticas de igualdad entrevistadas coincidían en la importancia de dotar de prioridad política a las medidas de igualdad. Sin embargo, la realidad de dicha priorización no era confirmada por las técnicas de igualdad entrevistadas, que reflejaban, al igual que una de las responsables políticas, la ausencia de relevancia de la igualdad frente a asuntos acuciantes como la crisis económica. Se observaba, por otro lado, una importante incorporación de mujeres que nunca habían trabajado a programas de empleo, precisamente por el impacto de la crisis en su hogar.

Por su parte, las asociaciones entrevistadas tenían dificultades para identificar la actividad municipal en materia de igualdad en el empleo, excepto en uno de los casos, donde las entrevistadas eran notablemente críticas con dichas actuaciones. De forma global, el conjunto de los municipios fue crítico con la participación del tejido sindical y empresarial, mientras se hizo

palpable el escaso interés y conocimiento de posibles acciones de igualdad por parte de estos actores, así como nula interacción entre organismos de igualdad con estos actores del ámbito laboral y con las concejalías responsable de las políticas de empleo.

\section{CONCLUSIONES}

A lo largo del estudio realizado, de forma global, se observa un escaso desarrollo del mainstreaming de género en el área de empleo en los municipios españoles. El uso de instrumentos de mainstreaming no es amplio y presenta importantes déficits en su implementación, como la falta de planificación presupuestaria, de evaluación o desagregación de datos que permita responder a las desiguales y diferentes realidades de empleo en los diferentes municipios. En este sentido, sin embargo, observados déficits semejantes en instancias 
supramunicipales, no cabría necesariamente relacionarlos con las bajas capacidades municipales, sino, quizá, con la falta de prioridad descrita y la baja calidad en el desarrollo de políticas de género españolas de forma sistémica.

La principal observación que cabe extraer de los datos analizados es que las líneas de trabajo implementadas continúan estando focalizadas en el desarrollo de actuaciones dirigidas a mejorar la empleabilidad y la inserción laboral de las mujeres con un importante enfoque hacia la vulnerabilidad social - a través del empleo por cuenta ajena o el emprendimiento-, pese a que los municipios parecen identificar en sus planes una gama más amplia de acciones deseables.

La dependencia de la financiación recibida desde instituciones supramunicipales, alineada con las prioridades políticas europeas en la materia, se identifica como una de las principales motivaciones. Se reproducen, así, algunos de los déficits citados por la literatura internacional y nacional en materia de empleo y género, dirigiendo las políticas hacia la incorporación de las mujeres en entornos laborales masculinizados, pero escasamente dirigidas a que se induzca un cambio en el mercado laboral derivado de la incorporación de las mujeres, como muestra el ínfimo desarrollo de acciones dirigidas a valorizar trabajos típicamente femeninos o dirigidas a luchar contra el conocido «techo de cristal», entre otras acciones anteriormente citadas.

Pese a ello, se observa un incipiente desarrollo por parte de los municipios de líneas de trabajo en el marco de las políticas de responsabilidad social corporativa, tanto dirigidas a la propia Administración — como el desarrollo de contratación con cláusulas de género- como orientadas al entorno empresarial, a través del apoyo a la realización de planes de igualdad en empresas y el desarrollo de acciones con personas que ya trabajan y que conviven con grandes problemáticas en materia de conciliación y corresponsabilidad. El punto de partida de muchas de estas actuaciones se sitúa con la promulgación de la ley estatal de igualdad 3/2007 del 22 de marzo, observándose, por tanto, un impacto positivo de la legislación estatal en el ámbito local.

Resulta sin embargo más complejo definir el rol de los municipios en una política de igualdad en el empleo de carácter multinivel según los datos recogidos. Se observa un ínfimo desarrollo de acciones relacionadas con usos de los tiempos, a pesar de que es el mandato más destacado que las legislaciones regionales y estatales emiten para el ámbito local. Asimismo, otras acciones relacionadas con la proximidad, como los puntos de atención a casos de discriminación, son también aspectos muy poco desarrollados. Por su parte, aspectos como la participación, si bien se trabajan de forma notable en los municipios a través de los consejos de Mujer y/o Igualdad y se conceden a ellos valoraciones positivas, presentan notables carencias en el ámbito sectorial de las políticas de empleo, pese a ser una de 
las políticas consideradas prioritarias. Se observan relaciones muy débiles con los principales actores en materia de empleo, tanto aquellos institucionales como ajenos a las instituciones, como sindicatos y asociaciones empresariales.

Parece, por tanto, necesario repensar las políticas desde una perspectiva verdaderamente participativa, donde se valoren las contribuciones de las arenas locales en el diseño de las políticas de igualdad en el empleo en aras a aprovechar sus potencialidades y observar complementariedades entre actuaciones públicas y los diferentes actores, fomentando el debate sobre los regímenes de género posibles que promueven las políticas.

En los actuales escenarios, en entornos donde visiones localistas y municipalistas presionan el conjunto del sistema político, cabría observar qué impacto tienen estas visiones en un mayor conocimiento de la realidad local y el desarrollo de roles propios por parte de las Administraciones locales en materia de igualdad en el empleo. Igualmente, se consideran relevantes futuras preguntas de investigación, aquellas relativas a la contribución de las instituciones locales y sus políticas al desarrollo de culturas organizacionales (pública y privadas) favorables a la igualdad, especialmente en las pymes, donde se encuentran los mayores porcentajes de empleo en muchos municipios, siendo más fácilmente accesibles desde las instituciones locales.

Si bien la crisis ha sido acompañada de retrocesos en el desarrollo de las políticas de igualdad, a la luz de los presentes resultados, podrían constituir un positivo punto de inicio en el análisis del impacto de las políticas actuales cuestiones como las visiones de igualdad en las organizaciones, los usos de los tiempos, así como los efectivos avances en materia de representación femenina en posiciones de poder en el ámbito del empleo o disminución de la brecha salarial, identificando buenas prácticas más allá de las grandes corporaciones. Asimismo, sería necesario atender a la segregación horizontal por género en los distintos sectores productivos, y a la escasa valoración (social y en términos de remuneración) de los sectores tradicionalmente feminizados, así como al impacto de estas cuestiones en la configuración del nuevo mercado de trabajo — más precario- que emerge tras la gran crisis.

En el proceso de reconstrucción de las políticas de igualdad tras su desmantelamiento se observa sin embargo una posible amenaza en la Ley 27/2013, de 27 de diciembre, de Racionalización y Sostenibilidad de la Administración Local. La literatura previamente citada observa posibles impactos en materia de financiación por el posible desajuste entre competencias a desarrollar y fondos disponibles. Los presentes resultados muestran notables déficits y sesgos en las políticas de igualdad en el empleo en un contexto favorable a las políticas de igualdad. En este contexto, sin embargo, los municipios ya reproducían las políticas supralocales, pese a identificar también otras posibles 
acciones, principalmente por su dependencia económica de otras administraciones. Cabría observar en futuras investigaciones en qué grado un posible cambio en las prioridades políticas se relaciona con la previsible dependencia presupuestaria de Administraciones supralocales.

Las posteriores elecciones municipales de 2015 han configurado un escenario novedoso, de proporciones y potencialidad todavía difíciles de determinar, en el que se ha observado una fuerte emergencia del municipalismo y la participación como ejes de los discursos electorales, así como un aparente foco en la transversalización del género de forma global, con propuestas que, en el caso de las políticas de empleo, se han encaminado a cubrir vacíos previos, proponiendo la gestión de horarios municipales o la financiación pública del cuidado de niños y niñas hasta los tres años, entre otras medidas. Se trata de actuaciones que serán objeto de investigación futura en el marco de la salida de la recesión y que deberán confirmar si finalmente se consolida la transformación de las políticas de género municipales hacia el desarrollo de un rol propio en el contexto multinivel de las políticas de igualdad.

\section{Bibliografía}

Acker, J. (1990). Hierarchies, jobs, bodies: A theory of gendered organizations. Gender and Society, 4 (2), 139-158. Disponible en: https://doi.org/10.1177/089124390004002002.

Alfama, E., y Quintana, I. (2007). Igualdad de género en el desarrollo local en España. Barcelona: IGOP.

Alonso, A. (2012). El mainstreaming de género en España. Cronología, instrumentos e impacto en las politicas finales. Santiago de Compostela: Universidad de Santiago de Compostela.

- (2008). La europeización de las políticas de género en el nivel subnacional: análisis del caso gallego. RIPS. Revista de Investigaciones Politicas y Sociológicas, 7 (2), 63-78

Alonso, A. y Paleo, N. (2014). ¿Es únicamente una cuestión de austeridad? Crisis económica y políticas de género en Espańa. Investigaciones Feministas, 5, 36-68.

Astelarra, J. (2005). Veinte años de políticas de igualdad. Valencia: Universidad de Valencia.

Boulding, E. (1976). Handbook of international data on women. S. 1.: Sage Publications.

Bustelo, M. (1999). Políticas públicas de igualdad de género en España: evolución y evaluación. En Género y ciudadanía: revisiones desde el ámbito privado: XII Jornadas de Investigación Interdisciplinaria (pp. 367-390). Madrid: Instituto Universitario de Estudios de la Mujer.

- (2004). La evaluación de las politicas de género en España. Madrid: Los Libros de la Catarata.

Carballada, Á. M. et al. (2005). Los pactos territoriales a favor del empleo en España. Boletín de La Asociación de Geógrafos Españoles, 39, 335-360.

Carrasco, C. (2001). Tiempos, trabajos y género (vol. 78). Barcelona: Edicions Universitat Barcelona.

Comisión Europea. (2001). Fomentar un marco europeo para la responsabilidad social de las empresas. Bruselas, 18-7-2001, COM (2001) 366 final. 
Comisión Europea. (2010). Europa 2020. Una estrategia para un crecimiento inteligente, sostenible e integrador. Bruselas, 3-3-2010, COM (2010) 2020 final.

Comisión Europea (2011), A Renewed EU Strategy 2011-14 for Corporate Social Responsibility. Brussels, 25-10-2011, COM (2011) 681 final.

Consejo de Europa. (1999). Mainstreaming de género. Marco conceptual, metodología y presentación de «buenas prácticas». Informe final de las actividades del Grupo de especialistas en mainstreaming (EG-S-MS). Madrid: Instituto de la Mujer, Ministerio de Trabajo y Asuntos Sociales.

Cooke, L. (2009). Gender equity and fertility in Italy and Spain. Journal of Social Policy, 38 (1), 123-140. Disponible en: https://doi.org/10.1017/S0047279408002584.

Díaz, X. et al. (2004). El trabajo se transforma: relaciones de producción y relaciones de género. Madrid: Centro de Estudios de la Mujer.

DiMaggio, P. J. y Powell, W. W. (2005). A gaiola de ferro revisitada: isomorfismo institucional e racionalidade coletiva nos campos organizacionais. RAE-Revista de Administração de Empresas, 45 (2), 74-89.

Diz, I. y Lois, M. I. (2011). La institucionalización de la igualdad de género en Galicia: un camino abierto. Gestión y Análisis de Políticas Públicas, 5, 145-164.

Esping-Andersen, G. (2002). Why we need a new welfare state. Oxford: Oxford University Press.

- (2008). Un nuevo equilibrio de bienestar. Politica y Sociedad, 44 (2), 11-30. Disponible en: https://doi.org/10.1093/0199256438.001.0001.

Gelambí, M. (2005). Les politiques de gènere als ajuntaments catalans: un procés en construcció (vol. 243). Barcelona: Institut de Ciències Polítiques i Socials.

Giráldez, T. (2004). La complejidad de las políticas municipales de género. Complejidad de las políticas municipales de género. En E. Roldán (ed.). Género, políticas locales e intervención social. Un análisis de los servicios de bienestar social municipal para la población femenina en España. Madrid: Editorial Complutense.

Grosser, K. y Moon, J. (2005). The role of corporate social responsibility in gender mainstreaming. International Feminist Journal of Politics, 7 (4), 532-554. Disponible en: https://doi.org/10.1080/14616740500284524.

Heras, M. A. D. (2006). Dependientes y cuidadores: el desafío de los próximos años. Revista del Ministerio de Trabajo e Inmigración, 60, 57-74.

Karamessini, M. y Rubery, J. (eds.) (2013). Women and Austerity. The Economic Crisis and the Future for Gender Equality. London: Routledge.

Liebert, U. (2003). Europeanization and the "Needle's Eye»: The Transformation of Employment Policy in Germany1. Review of Policy Research, 20 (3), 479-492. Disponible en: https://doi.org/10.1111/1541-1338.00032.

Lombardo, E. (2003). EU Gender Policy Trapped in the Wollstonecraft Dilemma? European Journal of Women's Studies, 10 (2), 159-180. Disponible en: https://doi.org/10.1177/13 50506803010002003.

- (2004). La europeización de la política española de igualdad de género. Valencia: Tirant lo Blanch.

Lombardo, E., y León, M. (2015). Políticas de igualdad de género y sociales en España: origen, desarrollo y desmantelamiento en un contexto de crisis económica. Investigaciones Feministas, 5, 13-35. Disponible en: https://doi.org/10.5209/rev_INFE.2014.v5.47986. 
Mayordomo, M., y Carrasco, C. (2000). Los modelos y estadísticas de empleo como construcción social: la encuesta de población activa y el sesgo de género. Política y Sociedad, 34, 101-112.

Miguélez, F. et al. (1999). Las relaciones de empleo en España. Madrid: Siglo XXI.

Miguélez, F. (2004). La flexibilidad laboral. Trabajo: Revista Andaluza de Relaciones Laborales, $13,17-36$.

Navarro, V. (ed.). (2004). El Estado de bienestar en España. Madrid: Tecnos.

Otero-Hermida, P. (2009). Acciones para la igualdad en el ámbito empresarial: las politicas públicas de RSC para PYME. Barcelona: Centro de Investigación Economía y Sociedad.

Otero-Hermida, P. (2016). El impacto de las politicas de género e igualdad en el empleo en el ámbito local. Santiago de Compostela: Universidad Santiago de Compostela.

Paleo, N. (2015). Las politicas municipales de género. Nivel de desarrollo y variables explicativas en el caso gallego [tesis doctoral]. Universidad de Santiago de Compostela

Prieto, C., y Miguélez, F. (2009). Trasformaciones del empleo, flexibilidad y relaciones laborales en Europa. Politica y Sociedad, 46 (1), 275-287.

Roldán, E. y Leyra, B. (2014). Reforma local, servicios sociales y perspectiva de género. Investigaciones feministas: papeles de estudios de mujeres, feministas y de género, 5, 129-156.

Roldán, E. (2004). Género, politicas locales e intervención social: un análisis de los servicios de bienestar social municipal para la población femenina en España. Madrid: Editorial Complutense.

Rubery, J. et al. (2002). Gender mainstreaming in European employment policy. Industrial Relations Journal, 33 (5), 500-522. Disponible en: https://doi.org/10.1111/14682338.00250.

Ruiz, J. A. A. (2004). La política de fomento del empleo: eje fundamental de las políticas activas de mercado de trabajo en España. Revista del Ministerio de Trabajo e Inmigración, 51, 15-30.

Ruiz, J. M. G. (2012). Los informes de Evaluación de Impacto de Género (IEIG) como garantía del gender mainstreaming y su incidencia en la normativa y jurisprudencia espańola. Revista Vasca de Administración Pública. Herri-Arduralaritzako Euskal Aldizkaria, 92, $17-55$.

Sampedro, M. R. (1992). Administración localy politicas de igualdad de la mujer. Madrid: Federación Española de Municipios y Provincias.

Sellers, J. M., y Lidström, A. (2007). Decentralization, local government, and the welfare state. Governance, 20 (4), 609-632. Disponible en: https://doi.org/10.1111/j.14680491.2007.00374.x.

Squires, J., y Wickham-Jones, M. (2002). Mainstreaming in Westminster and Whitehall: from Labour's ministry for women to the Women and Equality Unit. Parliamentary Affairs, 55 (1), 57-70. Disponible en: https://doi.org/10.1093/parlij/55.1.57.

Stratigaki, M. (2004). The cooptation of gender concepts in EU policies: The case of «Reconciliation of Work and Family». Social Politics: International Studies in Gender, State y Society, 11 (1), 30-56. Disponible en: https://doi.org/10.1093/sp/jxh025.

Subirats, J. y Gomá, R. (1998). La dimensión de estilo de las políticas públicas en España: entramados institucionales y redes de actores. En Politicas públicas en España: contenidos, redes de actores y niveles de gobierno (pp. 388-406). Barcelona: Ariel. 
Tobes, P., y Angoitia, M. (2005). La financiación autonómica de la segunda descentralización. Presupuesto y Gasto Público, 40, 97-112.

Tobes, P. (2002). El desarrollo de las políticas activas en España: Un análisis de los planes de acción para el empleo. Revista del Ministerio de Trabajo e Inmigración, 36, 15-44.

Unión General de Trabajadores. (2015). Trabajar igual, cobrar igual, conciliar igual. Madrid: UGT.

Vallés, J. M. y Brugué, Q. (2001). El gobierno local. En M. Alcántara y A. Martínez (eds.). Política y gobierno en España (pp. 267-302). Valencia: Tirant lo Blanch.

Verloo, M. et al. (2004). Framing the organization of intimacy as a policy problem accross Europe. Paper for the 2nd Pan-European Conference on European Politics of the ECPR Standing Group on European Union Politics, Bolonia, 24-26 de junio.

Walby, S. (2004). The European Union and gender equality: Emergent varieties of gender regime. Social Politics: International Studies in Gender, State and Society, 11 (1), 4-29. Disponible en: https://doi.org/10.1093/sp/jxh024.

- (2005). Gender mainstreaming: Productive tensions in theory and practice. Social Politics: International Studies in Gender, State y Society, 12 (3), 321-343. Disponible en: https://doi.org/10.1093/sp/jxi018. 